\title{
Probióticos e prebióticos: o estado da arte
}

\author{
Susana Marta Isay Saad* \\ Departamento de Tecnologia Bioquímico-Farmacêutica, Faculdade de Ciências Farmacêuticas, \\ Universidade de São Paulo
}

*Correspondência:

S. M. I. Saad

Departamento de Tecnologia

Bioquímico-Farmacêutica

Faculdade de Ciências Farmacêuticas

Universidade de São Paulo

Av. Prof. Lineu Prestes, 580

05508-000 - São Paulo, SP - Brasil

E-mail: susaad@usp.br
A microbiota intestinal humana exerce um papel importante tanto na saúde quanto na doença e a suplementação da dieta com probióticos e prebióticos pode assegurar o equilíbrio dessa microbiota. Probióticos são microrganismos vivos, administrados em quantidades adequadas, que conferem beneficios à saúde do hospedeiro. Prebióticos são carboidratos não-digeríveis, que afetam beneficamente o hospedeiro, por estimularem seletivamente a proliferação elou atividade de populações de bactérias desejáveis no cólon. Um produto referido como simbiótico é aquele no qual um probiótico e um prebiótico estão combinados. O presente artigo apresenta o estado da arte sobre probióticos e prebióticos, relatando novos conceitos, os benefícios que esses ingredientes alimentícios conferem à saúde humana e os possíveis mecanismos envolvidos, discutindo efeitos a eles atribuidos e salientando para novas descobertas relatadas, baseadas em evidências científicas. Outros aspectos, como a seleção e a aplicação de probióticos e de prebióticos, também são discutidos.

\section{INTRODUÇÃO}

Com o aumento na expectativa de vida da população, aliado ao crescimento exponencial dos custos médicohospitalares, a sociedade necessita vencer novos desafios, através do desenvolvimento de novos conhecimentos científicos e de novas tecnologias que resultem em modificações importantes no estilo de vida das pessoas. A nutrição precisa se adaptar a esses novos desafios, através do desenvolvimento de novos conceitos. A nutrição otimizada é um desses novos conceitos, dirigida no sentido de maximizar as funções fisiológicas de cada indivíduo,
Unitermos

- Probióticos

- Prebióticos

- Alimentos funcionais

- Lactobacillus

- Bifidobacterium

- Oligossacarídeos de maneira a assegurar tanto o bem-estar quanto a saúde, como também o risco mínimo de desenvolvimento de doenças ao longo da vida. Nesse contexto, os alimentos funcionais e especialmente os probióticos e prebióticos são conceitos novos e estimulantes (Roberfroid, 2002).

São considerados alimentos funcionais aqueles que, além de fornecerem a nutrição básica, promovem a saúde. Esses alimentos possuem potencial para promover a saúde através de mecanismos não previstos através da nutrição convencional, devendo ser salientado que esse efeito restringe-se à promoção da saúde e não à cura de doenças (Sanders, 1998). 
O trato gastrintestinal humano é um microecossistema cinético que possibilita o desempenho normal das funções fisiológicas do hospedeiro, a menos que microrganismos prejudiciais e potencialmente patogênicos dominem. Manter um equilíbrio apropriado da microbiota pode ser assegurado por uma suplementação sistemática da dieta com probióticos, prebióticos e simbióticos (Bielecka, Biedrzycka, Majkowska, 2002). Em virtude desse fato, nos últimos anos, o conceito de alimentos funcionais passou a concentrar-se de maneira intensiva nos aditivos alimentares que podem exercer efeito benéfico sobre a composição da microbiota intestinal (Ziemer, Gibson, 1998). Os prebióticos e os probióticos são atualmente os aditivos alimentares que compõem esses alimentos funcionais (Figura 1).

\section{PROBIÓTICOS, PREBIÓTICOS E SIMBIÓTICOS}

Os probióticos eram classicamente definidos como suplementos alimentares à base de microrganismos vivos, que afetam beneficamente o animal hospedeiro, promovendo o balanço de sua microbiota intestinal (Fuller, 1989).
Diversas outras definições de probióticos foram publicadas nos últimos anos (Sanders, 2003). Entretanto, a definição atualmente aceita internacionalmente é que eles são microrganismos vivos, administrados em quantidades adequadas, que conferem benefícios à saúde do hospedeiro (Food and Agriculture Organization of United Nations; World Health Organization, 2001; Sanders, 2003). A influência benéfica dos probióticos sobre a microbiota intestinal humana inclui fatores como efeitos antagônicos, competição e efeitos imunológicos, resultando em um aumento da resistência contra patógenos. Assim, a utilização de culturas bacterianas probióticas estimula a multiplicação de bactérias benéficas, em detrimento à proliferação de bactérias potencialmente prejudiciais, reforçando os mecanismos naturais de defesa do hospedeiro (Puupponen-Pimiä et al., 2002).

Prebióticos são componentes alimentares não digeríveis que afetam beneficamente o hospedeiro, por estimularem seletivamente a proliferação ou atividade de populações de bactérias desejáveis no cólon. Adicionalmente, o prebiótico pode inibir a multiplicação de patógenos, garantindo benefícios adicionais à saúde do hospedeiro. Esses componentes atuam mais freqüentemente no intestino

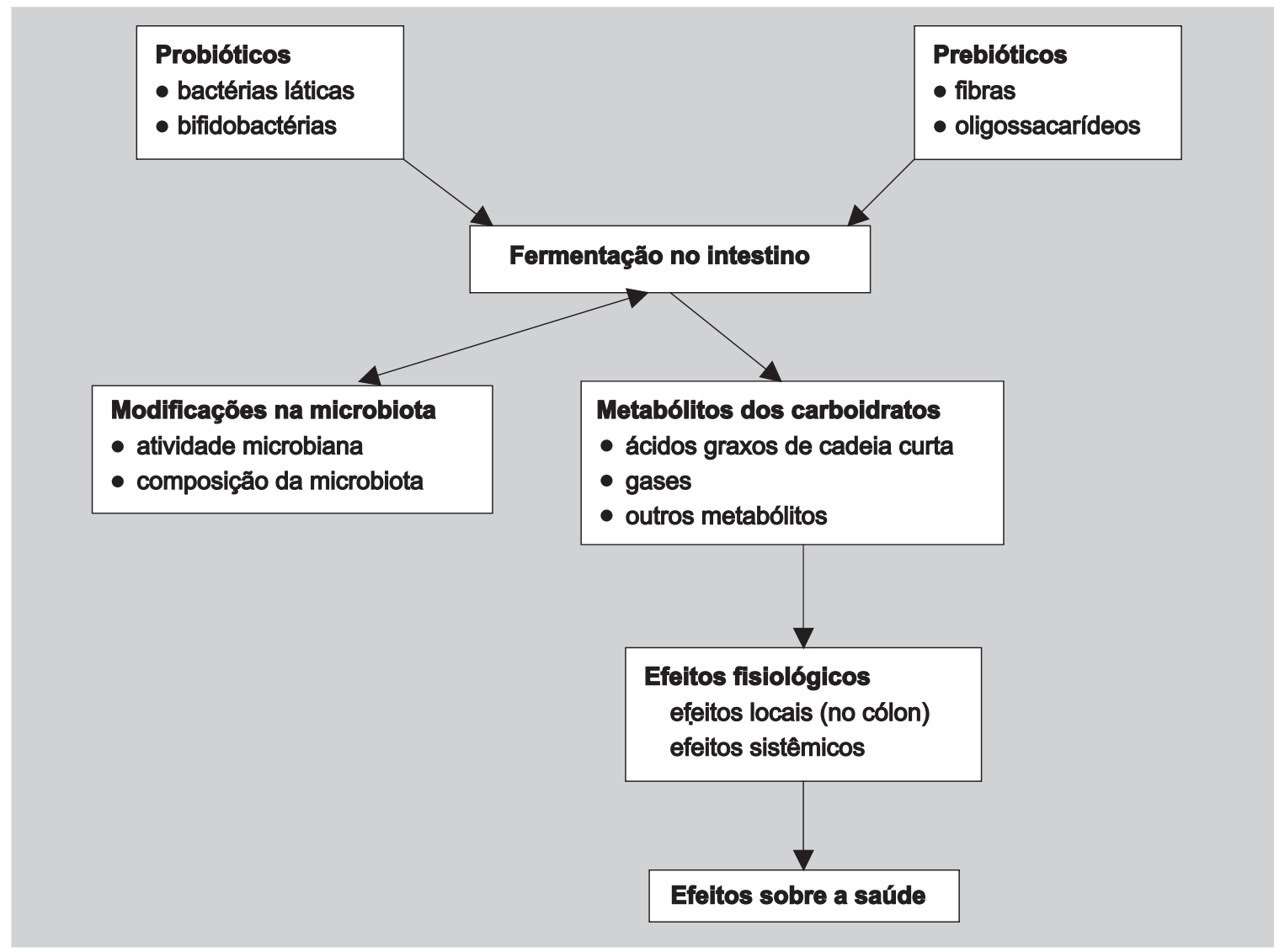

FIGURA 1 - Reações dos ingredientes alimentares probióticos e prebióticos com a microbiota intestinal, relativo a seus efeitos sobre a saúde. Adaptado de Puupponen-Pimiä et al. (2002). 
grosso, embora eles possam ter também algum impacto sobre os microrganismos do intestino delgado (Gibson, Roberfroid, 1995; Roberfroid, 2001; Gilliland, 2001; Mattila-Sandholm et al., 2002).

Um produto referido como simbiótico é aquele no qual um probiótico e um prebiótico estão combinados. A interação entre o probiótico e o prebiótico in vivo pode ser favorecida por uma adaptação do probiótico ao substrato prebiótico anterior ao consumo. Isto pode, em alguns casos, resultar em uma vantagem competitiva para o probiótico, se ele for consumido juntamente com o prebiótico. Alternativamente, esse efeito simbiótico pode ser direcionado às diferentes regiões "alvo" do trato gastrintestinal, os intestinos delgado e grosso. O consumo de probióticos e de prebióticos selecionados apropriadamente pode aumentar os efeitos benéficos de cada um deles, uma vez que o estímulo de cepas probióticas conhecidas leva à escolha dos pares simbióticos substrato-microrganismo ideais (Holzapfel, Schillinger, 2002; Puupponen-Pimiä et al., 2002; Mattila-Sandholm et al., 2002; Bielecka, Biedrzyck, Majkowska, 2002).

\section{AS FIBRAS E OS PREBIÓTICOS}

As fibras da dieta estão incluídas na ampla categoria dos carboidratos. Elas podem ser classificadas como solúveis, insolúveis ou mistas, podendo ser fermentáveis ou não-fermentáveis. A nova definição de fibra da dieta sugere a inclusão de oligossacarídeos e de outros carboidratos não-digeríveis. Deste modo, a inulina e a oligofrutose, denominadas de frutanos, são fibras solúveis e fermentáveis, as quais não são digeríveis pela $\alpha$-amilase e por enzimas hidrolíticas, como a sacarase, a maltase e a isomaltase, na parte superior do trato gastrintestinal (Carabin, Flamm, 1999).

Como os componentes da fibra da dieta não são absorvidos, eles penetram no intestino grosso e fornecem substrato para as bactérias intestinais. As fibras solúveis são normalmente fermentadas rapidamente, enquanto as insolúveis são lentamente ou apenas parcialmente fermentadas (Puupponen-Pimiä et al., 2002). A extensão da fermentação das fibras solúveis depende de sua estrutura física e química. A fermentação é realizada por bactérias anaeróbicas do cólon, levando à produção de ácido lático, ácidos graxos de cadeia curta e gases. Conseqüentemente, há redução do $\mathrm{pH}$ do lúmen e estimulação da proliferação de células epiteliais do cólon (Carabin, Flamm, 1999).

Os prebióticos identificados atualmente são carboidratos não-digeríveis, incluindo a lactulose, a inulina e diversos oligossacarídeos que fornecem carboidratos que as bactérias benéficas do cólon são capazes de fermentar.
Os prebióticos avaliados em humanos constituem-se dos frutanos e dos galactanos (Cummingns, Macfarlane, 2002). A maioria dos dados da literatura científica sobre efeitos prebióticos relaciona-se aos fruto-oligossacarídeos (FOS) e à inulina e diversos produtos comerciais estão disponíveis há vários anos (Puupponen-Pimiä et al., 2002). A inulina e a oligofrutose pertencem a uma classe de carboidratos denominados frutanos e são considerados ingredientes funcionais, uma vez que exercem influência sobre processos fisiológicos e bioquímicos no organismo, resultando em melhoria da saúde e em redução no risco de aparecimento de diversas doenças, conforme ilustrado na figura 1. As principais fontes de inulina e oligofrutose empregadas na indústria de alimentos são a chicória (Cichorium intybus) e a alcachofra de Jerusalém (Helianthus tuberosus) (Carabin, Flamm, 1999; Kaur, Gupta, 2002).

Frutano é um termo genérico empregado para descrever todos os oligo ou polissacarídeos de origem vegetal e refere-se a qualquer carboidrato em que uma ou mais ligações frutosil-frutose predominam dentre as ligações glicosídicas. Os frutanos são polímeros de frutose linear ou ramificada ligados por ligações $\beta(2 \rightarrow 1)$ ou $\beta(2 \rightarrow 6)$, encontradas, respectivamente, na inulina e nos frutanos do tipo levanos (Carabin, Flamm, 1999).

Os frutanos do tipo inulina dividem-se em dois grupos gerais: a inulina e os compostos a ela relacionados - a oligofrutose e os fruto-oligossacarídeos (FOS). A inulina, a oligofrutose e os FOS são entidades quimicamente similares, com as mesmas propriedades nutricionais. Essas semelhanças química e nutricional são conseqüentes à estrutura básica (ligações $\beta(2 \rightarrow 1)$ de unidades frutosil, algumas vezes terminadas em uma unidade glicosil), bem como à sua via metabólica em comum. A única diferença entre a inulina, a oligofrutose e os FOS sintéticos é o grau de polimerização, ou seja, o número de unidades individuais de monossacarídeos que compõem a molécula (Carabin, Flamm, 1999).

A inulina é um carboidrato polidisperso, constituído de subunidades de frutose ( 2 a 150), ligadas entre si e a uma glicose terminal, apresentando um grau médio de polimerização de 10 ou mais. A oligofrutose e os FOS são termos sinônimos utilizados para denominar frutanos do tipo inulina com grau de polimerização inferior a 10. Seus nomes derivam de oligossacarídeos (carboidratos com menos de 10 subunidades de monossacarídeos) compostos predominantemente de frutose. O termo oligofrutose é mais freqüentemente empregado na literatura para descrever inulinas de cadeia curta, obtidas por hidrólise parcial da inulina da chicória. O termo FOS tende a descrever misturas de frutanos do tipo inulina de cadeia 
curta, sintetizados a partir da sacarose. Os FOS consistem de moléculas de sacarose, compostas de duas ou três subunidades de frutose adicionais, adicionadas enzimaticamente, através de ligação $\beta(2 \rightarrow 1)$ à subunidade frutose da sacarose (Carabin, Flamm, 1999; Biedrzycka, Bielecka, 2004).

Os frutanos são os polissacarídeos não-estruturais mais abundantes na natureza, após o amido. Eles estão presentes em grande variedade de vegetais e, também, em algumas bactérias e fungos (Carabin, Flamm, 1999).

Bifidobactérias fermentam seletivamente os frutanos, preferencialmente a outras fontes de carboidratos, como o amido, a pectina ou a polidextrose (Fooks, Fuller, Gibson, 1999). A alta especificidade dos FOS como substratos para bifidobactérias resulta da atividade das enzimas $\beta$-frutosidases (inulinases) associadas a células específicas, as quais hidrolisam monômeros de frutose da extremidade não-redutora da cadeia de inulina ou de determinados açúcares em que o resíduo de frutose ocorre na posição $\beta(2-1)$. Essas hidrolases são produzidas por alguns bolores e leveduras e só esporadicamente por bactérias (Biedrzycka, Bielecka, 2004).

A velocidade de fermentação e a atividade de carboidratos não-digeríveis são fatores primordiais para a saúde intestinal do hospedeiro. Novos tipos de oligossacarídeos com velocidades de fermentação controladas serão desenvolvidos, de modo a assegurar a fermentação uniforme, ao longo do cólon, da área proximal para a distal (Puupponen-Pimiã et al., 2002).

\section{PRINCIPAIS BACTÉRIAS EMPREGADAS NOS ALIMENTOS FUNCIONAIS PROBIÓTICOS}

Bactérias pertencentes aos gêneros Lactobacillus e Bifidobacterium e, em menor escala, Enterococcus faecium, são mais freqüentemente empregadas como suplementos probióticos para alimentos, uma vez que elas têm sido isoladas de todas as porções do trato gastrintestinal do humano saudável. O íleo terminal e o cólon parecem ser, respectivamente, o local de preferência para colonização intestinal dos lactobacilos e bifidobactérias (Charteris et al., 1998; Bielecka et al., 2002). Entretanto, deve ser salientado que o efeito de uma bactéria é específico para cada cepa, não podendo ser extrapolado, inclusive para outras cepas da mesma espécie (Guarner, Malagelada, 2003).

Dentre as bactérias pertencentes ao gênero Bifidobacterium, destacam-se $B$. bifidum, $B$. breve, $B$. infantis, B. lactis, B. animalis, B. longum e $B$. thermophilum. Dentre as bactérias láticas pertencentes ao gênero Lactobacillus, destacam-se Lb. acidophilus, $L b$. helveticus, Lb. casei - subsp. paracasei e subsp. tolerans, $L b$. paracasei, $L b$. fermentum, $L b$. reuteri, $L b$. johnsonii, Lb. plantarum, Lb. rhamnosus e Lb. salivarius (Collins, Thornton, Sullivan, 1998; Lee et al., 1999; Sanders, Klaenhammer, 2001).

\section{OS PROBIÓTICOS E PREBIÓTICOS E A MICROBIOTA INTESTINAL}

Em condições normais, inúmeras espécies de bactérias estão presentes no intestino, a maioria delas anaeróbias estritas. Essa composição torna o intestino capaz de responder a possíveis variações anatômicas e físico-químicas (Lee et al., 1999). A microbiota intestinal exerce influência considerável sobre série de reações bioquímicas do hospedeiro. Paralelamente, quando em equilíbrio, impede que microrganismos potencialmente patogênicos nela presentes exerçam seus efeitos patogênicos. Por outro lado, o desequilíbrio dessa microbiota pode resultar na proliferação de patógenos, com conseqüente infecção bacteriana (Ziemer, Gibson, 1998).

A microbiota saudável é definida como a microbiota normal que conserva e promove o bem-estar e a ausência de doenças, especialmente do trato gastrintestinal. A correção das propriedades da microbiota autóctone desbalanceada constitui a racionalidade da terapia por probióticos (Isolauri, Salminen, Ouwehand, 2004). A influência benéfica dos probióticos sobre a microbiota intestinal humana inclui fatores como os efeitos antagônicos e a competição contra microrganismos indesejáveis e os efeitos imunológicos (Puupponen-Pimiä et al., 2002). Dados experimentais indicam que diversos probióticos são capazes de modular algumas características da fisiologia digestiva, como a imunidade da mucosa e a permeabilidade intestinal (Fioramonti, Theodorou, Bueno, 2003). A ligação de bactérias probióticas aos receptores da superfície celular dos enterócitos também dá início às reações em cascata que resultam na síntese de citocinas (Kaur, Chopra, Saini, 2002).

O conhecimento da microbiota intestinal e suas interações levou ao desenvolvimento de estratégias alimentares, objetivando a manutenção e o estímulo das bactérias normais ali presentes (Gibson, Fuller, 2000). É possível aumentar o número de microrganismos promotores da saúde no trato gastrintestinal (TGI), através da introdução de probióticos pela alimentação ou com o consumo de suplemento alimentar prebiótico, o qual irá modificar seletivamente a composição da microbiota, fornecendo ao probiótico vantagem competitiva sobre outras bactérias do ecossistema (Crittenden, 1999). 


\section{AS VANTAGENS NUTRICIONAIS E OS MECANISMOS DE ATUAÇÃO DOS PREBIÓTICOS E PROBIÓTICOS}

Embora os prebióticos e os probióticos possuam mecanismos de atuação em comum, especialmente quanto à modulação da microbiota endógena, eles diferem em sua composição e em seu metabolismo. O destino dos prebióticos no trato gastrintestinal é mais conhecido do que o dos probióticos. Assim como ocorre no caso de outros carboidratos não-digeríveis, os prebióticos exercem um efeito osmótico no trato gastrintestinal, enquanto não são fermentados. Quando fermentados pela microbiota endógena, o que ocorre no local em que exercem o efeito prebiótico, eles aumentam a produção de gás. Portanto, os prebióticos apresentam o risco teórico de aumentar a diarréia em alguns casos (devido ao efeito osmótico) e de serem pouco tolerados por pacientes com síndrome do intestino irritável. Entretanto, a tolerância de doses baixas de prebióticos é geralmente excelente. Os probióticos, por outro lado, não apresentam esse inconveniente teórico e têm sido efetivos na prevenção e no alívio de diversos episódios clínicos, envolvendo diarréia (Marteau, BoutronRuault, 2002).

Três possíveis mecanismos de atuação são atribuídos aos probióticos, sendo o primeiro deles a supressão do número de células viáveis através da produção de compostos com atividade antimicrobiana, a competição por nutrientes e a competição por sítios de adesão. O segundo desses mecanismos seria a alteração do metabolismo microbiano, através do aumento ou da diminuição da atividade enzimática. $O$ terceiro seria o estímulo da imunidade do hospedeiro, através do aumento dos níveis de anticorpos e o aumento da atividade dos macrófagos. $\mathrm{O}$ espectro de atividade dos probióticos pode ser dividido em efeitos nutricionais, fisiológicos e antimicrobianos (Fuller, 1989).

Assim como ocorre no caso de outras fibras da dieta, prebióticos como a inulina e a oligofrutose, são resistentes à digestão na parte superior do trato intestinal, sendo subseqüentemente fermentados no cólon. Eles exercem um efeito de aumento de volume, como conseqüência do aumento da biomassa microbiana que resulta de sua fermentação, bem como promovem um aumento na freqüência de evacuações, efeitos estes que confirmam a sua classificação no conceito atual de fibras da dieta. Quando adicionados como ingredientes funcionais a produtos alimentícios normais, prebióticos típicos, como a inulina e a oligofrutose, modulam a composição da microbiota intestinal, a qual exerce um papel primordial na fisiologia gastrintestinal (Roberfroid, 2002). Essa modulação da microbiota intes- tinal por esses prebióticos é conseqüente à alteração da composição dessa microbiota por uma fermentação específica, a qual resulta em uma comunidade em que há predomínio de bifidobactérias (Kaur, Gupta, 2002).

A Figura 2 mostra o destino dos probióticos e dos prebióticos no organismo humano, os prebióticos como fatores bifidogênicos e os principais mecanismos de atuação dos probióticos.

\section{OS EFEITOS ATRIBUÍDOS AOS PROBIÓTICOS E PREBIÓTICOS}

Os benefícios à saúde do hospedeiro atribuídos à ingestão de culturas probióticas que mais se destacam são: controle da microbiota intestinal; estabilização da microbiota intestinal após o uso de antibióticos; promoção da resistência gastrintestinal à colonização por patógenos; diminuição da população de patógenos através da produção de ácidos acético e lático, de bacteriocinas e de outros compostos antimicrobianos; promoção da digestão da lactose em indivíduos intolerantes à lactose; estimulação do sistema imune; alívio da constipação; aumento da absorção de minerais e produção de vitaminas. Embora ainda não comprovados, outros efeitos atribuídos a essas culturas são a diminuição do risco de câncer de cólon e de doença cardiovascular. São sugeridos, também, a diminuição das concentrações plasmáticas de colesterol, efeitos anti-hipertensivos, redução da atividade ulcerativa de Helicobacter pylori, controle da colite induzida por rotavirus e por Clostridium difficile, prevenção de infecções urogenitais, além de efeitos inibitórios sobre a mutagenicidade (Shah, Lankaputhra, 1997; Charteris et al., 1998; Jelen, Lutz, 1998; Klaenhammer, 2001; Kaur, Chopra, Saini, 2002; Tuohy et al., 2003).

Alguns efeitos atribuídos aos prebióticos são a modulação de funções fisiológicas chaves, como a absorção de cálcio e, possivelmente, o metabolismo lipídico, a modulação da composição da microbiota intestinal, a qual exerce um papel primordial na fisiologia gastrintestinal, e a redução do risco de câncer de cólon (Roberfroid, 2002). Diversos estudos experimentais mostraram a aplicação da inulina e da oligofrutose como fatores bifidogênicos, ou seja, que estimulam a predominância de bifidobactérias no cólon. Conseqüentemente, há um estímulo do sistema imunológico do hospedeiro, uma redução nos níveis de bactérias patogênicas no intestino, um alívio da constipação, uma diminuição do risco de osteoporose resultante da absorção diminuída de minerais, particularmente o cálcio. Adicionalmente, haveria uma redução do risco de arteriosclerose, através da diminuição na síntese de triglicérides e ácidos graxos no figado e diminuição do nível desses compostos no sangue (Kaur, Gupta, 2002). 


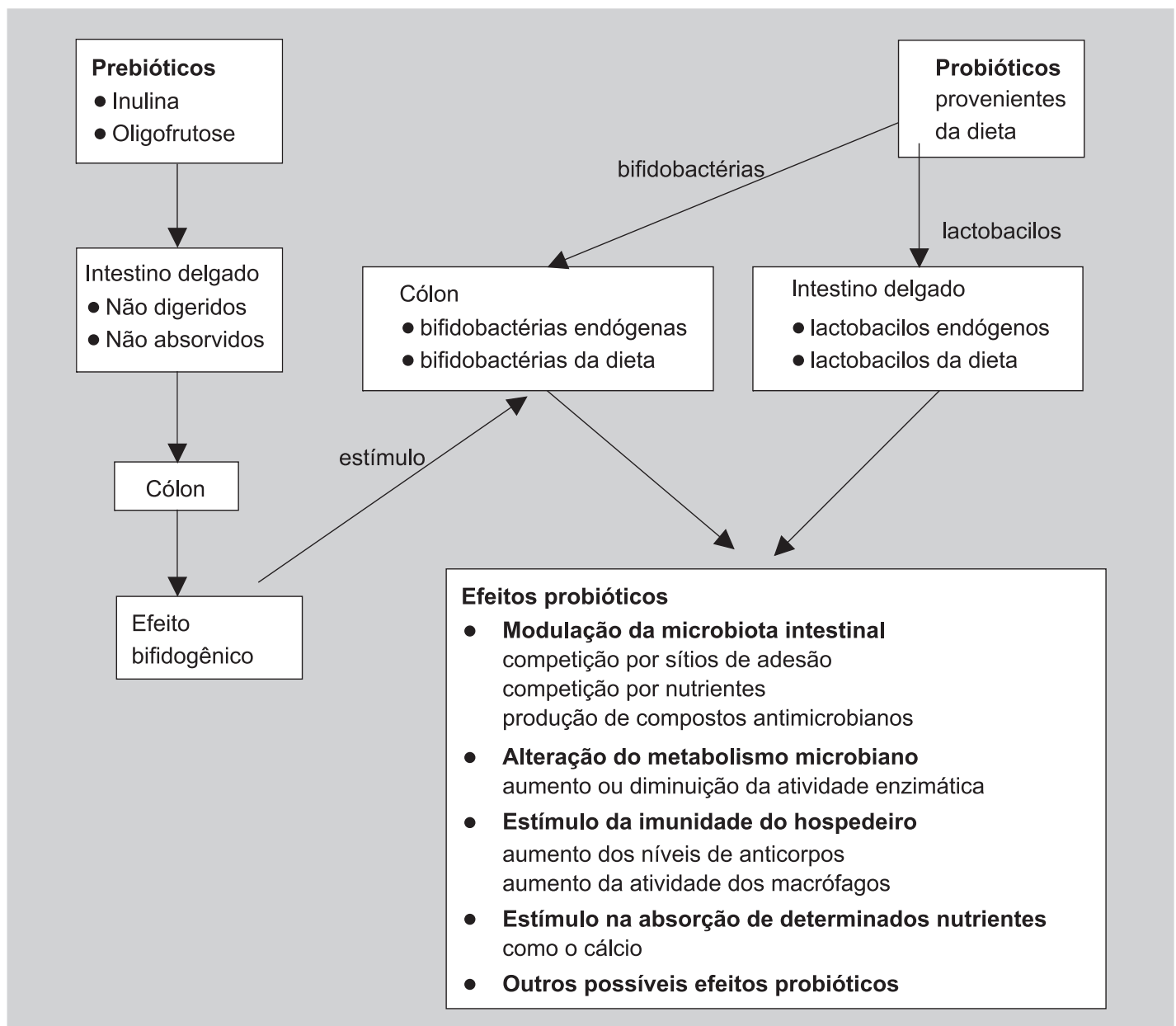

FIGURA 2 - Os prebióticos como fatores bifidogênicos e os mecanismos de atuação dos probióticos

\section{A MODULAÇÃO DA MICROBIOTA INTESTINAL E ALTERAÇÃO DO METABOLISMO MICROBIANO}

A resistência aumentada contra patógenos é a característica mais promissora no desenvolvimento de probióticos eficazes. O emprego de culturas probióticas exclui microrganismos potencialmente patogênicos e reforça os mecanismos naturais de defesa do organismo (Puupponen-Pimiä et al., 2002). A modulação da microbiota intestinal pelos microrganismos probióticos ocorre através de um mecanismo denominado "exclusão competitiva". Esse mecanismo impede a colonização dessa mucosa por microrganismos potencialmente patogênicos, através da competição por sítios de adesão, da competição por nutrientes e/ou da produção de compostos antimicrobianos (Kaur, Chopra, Saini, 2002; Guarner, Malagelada, 2003).

Os probióticos auxiliam a recompor a microbiota intestinal, através da adesão e colonização da mucosa intestinal, ação esta que impede a adesão e subseqüente produ- ção de toxinas ou invasão das células epiteliais (dependendo do mecanismo de patogenicidade) por bactérias patogênicas. Adicionalmente, os probióticos competem com as bactérias indesejáveis pelos nutrientes disponíveis no nicho ecológico. O hospedeiro fornece as quantidades de nutrientes que as bactérias intestinais necessitam e estas indicam ativamente as suas necessidades. Essa relação simbiótica impede uma produção excessiva de nutrientes, a qual favoreceria o estabelecimento de competidores microbianos com potencial patogênico ao hospedeiro. Além disso, os probióticos podem impedir a multiplicação de seus competidores, através de compostos antimicrobianos, principalmente as bacteriocinas (Kopp-Hoolihan, 2001; Calder, Kew, 2002; Guarner, Malagelada, 2003).

Microbiota intestinal desbalanceada causa alterações como a diarréia associada a infecções ou ao tratamento por antibióticos, a alergia alimentar, o eczema atópico, doenças inflamatórias intestinais e artrite. Assim sendo, a correção das propriedades de uma microbiota autóctone em desequilíbrio constitui-se a base da terapia por probióticos (Isolauri, Salminen, Ouwehand, 2004). 
No caso específico de pacientes que sofrem da síndrome do intestino irritável, há evidências de que a microbiota intestinal desses pacientes é alterada, promovendo fermentação anormal no cólon. Embora ainda não esteja claro se uma relação causal nesse sentido existe ou se a microbiota alterada é conseqüência de uma disfunção intestinal, a restauração do equilíbrio dessa microbiota, através da administração de probióticos, pode resultar em benefícios terapêuticos (Verdu, Collins, 2004).

As bactérias intestinais estão envolvidas em grande variedade de atividades metabólicas e essas atividades sofrem alterações pela dieta. É importante destacar que algumas das atividades metabólicas estão associadas à síntese de compostos carcinogênicos e determinados estudos mostram que as bactérias probióticas podem auxiliar na degradação de alguns desses compostos (Morotomi, 1997).

A alteração do metabolismo microbiano pelos probióticos ocorre por meio do aumento ou diminuição da atividade enzimática. Uma função vital das bactérias láticas na microbiota intestinal é produzir a enzima $\beta$-Dgalactosidade, auxiliando a quebra da lactose no intestino. Essa ação é fundamental, particularmente no caso de indivíduos com intolerância à lactose, os quais são incapazes de digeri-la adequadamente, o que resulta em desconforto abdominal em grau variável (Lourens-Hattingh, Viljoen, 2002). Diversas evidências têm demonstrado que o consumo de quantidades adequadas, de cepas apropriadas de bactérias láticas (incluindo bactérias láticas nãoprobióticas como Lactobacillus bulgaricus e Streptococcus thermophilus) é capaz de aliviar os sintomas de intolerância à lactose. Desta maneira, conseguese incorporar produtos lácteos e os nutrientes importantes que fazem parte desses produtos de volta à dieta de indivíduos intolerantes à lactose, anteriormente obrigados a restringir a ingestão desses produtos. Outros efeitos descritos foram a redução ou supressão da atividade de enzimas fecais, como a $\beta$-glicuronidase, a nitrorredutase, a azorredutase (Lee et al., 1999; Kopp-Hoolihan, 2001).

\section{O ESTÍMULO DA IMUNIDADE DO HOSPEDEIRO E DA ABSORÇÃO E BIODISPONIBILIDADE DE DETERMINADOS NUTRIENTES}

O efeito dos probióticos sobre a resposta imune tem sido bastante estudado. Grande parte das evidências de sistemas in vitro e de modelos animais e humanos sugere que os probióticos podem estimular tanto a resposta imune não-específica quanto específica. Acredita-se que esses efeitos sejam mediados por uma ativação dos macrófagos, por um aumento nos níveis de citocinas, por um aumento da atividade das células destruidoras naturais (NK - "natural killer") e/ou dos níveis de imunoglobulinas. Merece destaque o fato de que esses efeitos positivos dos probióticos sobre o sistema imunológico ocorrem sem o desencadeamento de uma resposta inflamatória prejudicial. Entretanto, nem todas as cepas de bactérias láticas são igualmente efetivas. A resposta imune pode ser aumentada, quando um ou mais probióticos são consumidos concomitantemente e atuam sinergisticamente, como parece ser o caso dos Lactobacillus administrados em conjunto com Bifidobacterium (Kopp-Hoolihan, 2001; Calder, Kew, 2002; Van de Water, 2003).

A microbiota intestinal pode conferir atividade imunomodulatória durante uma idade crítica ou um período da vida crítico, quando aberrações imunorregulatórias podem induzir doenças clínicas. Não se conhece, com precisão, o quanto propriedades probióticas, como a aderência e a colonização, são requeridas para que essa atividade imunomodulatória ocorra. Para a imunorregulação, propriedades específicas de aderência podem ser requeridas. A colonização parece estar associada com a maturação dos mecanismos de imunidade humoral, uma vez que há relatos de que recém-nascidos colonizados por Bacteroides fragilis e Bifidobacterium spp. apresentavam mais células secretoras de $\operatorname{IgA}$ e IgM circulantes. Esses resultados sugerem que a microbiota intestinal humana é importante na imunorregulação e que diferenças qualitativas na composição dessa microbiota podem alterar a homeostase imunológica do indivíduo (Isolauri, Salminen, Ouwehand, 2004).

A ação de microrganismos durante a fabricação de produtos contendo culturas ou no trato digestivo influencia favoravelmente a quantidade, a biodisponibilidade e a digestibilidade de alguns nutrientes da dieta. A fermentação de produtos lácteos por bactérias láticas pode aumentar a concentração de determinados nutrientes, como vitaminas do complexo B. As bactérias láticas caracterizamse pela liberação de diversas enzimas no lúmen intestinal. Essas enzimas exercem efeitos sinérgicos sobre a digestão, aliviando sintomas de deficiência na absorção de nutrientes (Kopp-Hoolihan, 2001).

A hidrólise enzimática bacteriana pode aumentar a biodisponibilidade de proteínas e de gordura e aumentar a liberação de aminoácidos livres. Além de ácido lático, ácidos graxos de cadeia curta, como propiônico e butírico, também são produzidos pelas bactérias láticas. Quando absorvidos, esses ácidos graxos contribuem para o pool de energia disponível do hospedeiro e podem proteger contra mudanças patológicas na mucosa do cólon. Além disso, uma concentração mais elevada de ácidos graxos de ca- 
deia curta auxilia na manutenção de um $\mathrm{pH}$ apropriado no lúmen do cólon, crucial para a expressão de muitas enzimas bacterianas sobre compostos estranhos e sobre o metabolismo de carcinógenos no intestino (Kopp-Hoolihan, 2001). Assim, a produção de ácido butírico por algumas bactérias probióticas neutraliza a atividade de alguns carcinógenos da dieta, como as nitrosaminas, resultantes da atividade metabólica de bactérias comensais em indivíduos que consomem dietas com alto teor de proteínas (Wollowski, Rechkemmer, Pool-Zobel, 2001).

\section{OUTROS POSSÍVEIS EFEITOS ATRIBUÍDOS ÀS CULTURAS PROBIÓTICAS}

Outros possíveis efeitos dos probióticos são a sua atuação na prevenção de câncer, na modulação de reações alérgicas, na melhoria da saúde urogenital de mulheres (Kopp-Hoolihan, 2001) e nos níveis sanguíneos de lipídeos (Pereira, Gibson, 2002). Além desses possíveis efeitos, evidências preliminares indicam que bactérias probióticas ou seus produtos fermentados podem exercer um papel no controle da pressão sanguínea. Estudos clínicos e com animais documentaram efeitos anti-hipertensivos com a ingestão de probióticos (Kopp-Hoolihan, 2001).

É provável que o efeito benéfico dos probióticos na modulação de reações alérgicas seja exercido através do desenvolvimento da função de barreira da mucosa. Outra possibilidade é que um estímulo microbiano reduzido durante a primeira infância resulte em maturação mais lenta do sistema imune, tendo em vista o fato de que foi observado que crianças alérgicas eram menos freqüentemente colonizadas por lactobacilos, predominando os coliformes e Staphylococcus aureus. Assim sendo, os probióticos são capazes de atenuar a inflamação intestinal e as reações de hipersensibilidade em pacientes com alergia alimentar, funcionando como um meio de prevenção primária da alergia em indivíduos suscetíveis (KoppHoolihan, 2001; Van de Water, 2003).

Quanto ao efeito probiótico benéfico sobre a concentração sanguínea de lipídios, apesar de poucos estudos clínicos de curta duração terem sido realizados, todos mostraram que a ingestão de probióticos exerceu influência sobre os lipídios de uma maneira similar, reduzindo os níveis de colesterol total, de colesterol LDL e de triglicérides (KoppHoolihan, 2001). As bactérias probióticas fermentam os carboidratos não-digeríveis provenientes dos alimentos no intestino. Os ácidos graxos de cadeia curta resultantes dessa fermentação possivelmente causam diminuição das concentrações sistêmicas dos lipídeos sanguíneos, através da inibição da síntese de colesterol hepático e/ou da redistribuição do colesterol do plasma para o fígado (Pereira, Gibson,
2002). Entretanto, é importante salientar que diversas outras hipóteses têm sido levantadas e que o efeito real dos probióticos no controle de colesterol ainda é questionável (Lourens-Hattingh, Viljoen, 2001).

Tanto as bactérias patogênicas como probióticas podem entrar no trato urogenital através de diversas vias. Entretanto, elas entram predominantemente através do cólon e reto via períneo. Após entrarem no cólon, os microrganismos probióticos podem alterar a sua microbiota favoravelmente e determinadas cepas podem atingir a vagina e o trato urinário como células viáveis (Reid et al., 2001). Assim sendo, a melhoria da saúde urogenital de mulheres pode ser atribuída ao fato de infecções do trato urinário e genital estarem freqüentemente associadas a bactérias do cólon. Desta maneira, o cólon funcionaria como fonte de microrganismos tanto benéficos como maléficos para os tratos urinário e genital. Entretanto, estudos clínicos controlados são necessários para substanciar esses achados preliminares (Kopp-Hoolihan, 2001; Vrese, Schrezenmeir, 2002).

A atuação dos probióticos na redução do risco de aparecimento de câncer é, possivelmente, realizada através da neutralização dos efeitos genotóxicos e mutagênicos. Entretanto, embora a pesquisa voltada à prevenção do câncer seja muito promissora, os resultados são, ainda, muito preliminares para se desenvolver recomendações dos probióticos nesse sentido (Kopp-Hoolihan, 2001). É possível que diferentes cepas utilizem diferentes mecanismos de ação. Assim, é necessário que mais trabalhos sejam realizados para identificar cepas específicas e características de cada cepa responsáveis por efeitos antitumor específicos e os mecanismos através dos quais esses efeitos são mediados (Rafter, 2003).

\section{POSSÍVEL MECANISMO DOS PROBIÓTICOS E DOS PREBIÓTICOS NA INIBIÇÃO DO CÂNCER DE CÓLON}

O câncer de cólon é uma das causas mais importantes de morbidade e mortalidade por câncer entre homens e mulheres. Criptas aberrantes são lesões precursoras putrefativas, a partir das quais os adenomas e carcinomas podem se desenvolver no cólon. Estudos com ratos mostraram que a administração de oligofrutose e inulina na dieta suprimiu significativamente o número de focos de criptas aberrantes no cólon, quando comparado à dieta controle. Essa inibição era mais pronunciada em ratos alimentados com inulina do que naqueles que recebiam oligofrutose. O papel desempenhado pela inulina e a oligofrutose na redução da formação das criptas aberrantes, um marcador pré-neoplásico precoce do poten- 
cial maligno no processo de carcinogênese do cólon, sugere que eles têm potencial para suprimir a carcinogênese no cólon. Essa prevenção provavelmente ocorre através da modificação da microbiota do cólon (Kaur, Gupta, 2002; Roberfroid, 2002). Entretanto, não há evidências em humanos de que os prebióticos sejam capazes de prevenir a iniciação do câncer de cólon (Wollowski, Rechkemmer, Pool-Zobel, 2001).

O mecanismo através do qual os probióticos poderiam inibir o desenvolvimento de câncer de cólon ainda são desconhecidos. Entretanto, vários mecanismos de atuação são sugeridos, incluindo o estímulo da resposta imune do hospedeiro, a ligação e a degradação de compostos com potencial carcinogênico, alterações qualitativas e/ou quantitativas na microbiota intestinal envolvidas na produção de carcinógenos e de promotores (ex: degradação de ácidos biliares), produção de compostos antitumorígenos ou antimutagênicos no cólon, alteração da atividade metabólica da microbiota intestinal, alteração das condições físicoquímicas do cólon e efeitos sobre a fisiologia do hospedeiro (Hirayama, Rafter, 2000; Rafter, 2003). As bifidobactérias, que colonizam o cólon em detrimento dos enteropatógenos, podem ligar-se ao carcinógeno final, promovendo sua remoção através das fezes (Kaur, Gupta, 2002).

\section{EFEITOS FISIOLÓGICOS DOS PRODUTOS DE FERMENTAÇÃO DOS PREBIÓTICOS NO TRATO GASTRINTESTINAL. OS PREBIÓTICOS E A CONSTIPAÇÃO INTESTINAL}

A inulina e a oligofrutose são ingredientes com baixo valor energético e, conseqüentemente, de baixo valor calórico (1 a $2 \mathrm{kcal} / \mathrm{g}$ ), sendo utilizados em dietas de pessoas obesas. Estudos in vivo realizados em animais mostraram que a suplementação da dieta com frutanos do tipo inulina diminuiu o pH do ceco e aumentou o tamanho do seu pool de ácidos graxos de cadeia curta, predominando o acetato, seguido do butirato e do propionato. Possivelmente, esse aumento está relacionado ao efeito dos frutanos sobre o tecido intestinal, levando a hiperplasia da mucosa e ao aumento da espessura da parede, tanto no intestino delgado quanto no ceco, fenômenos estes que são acompanhados de um aumento no fluxo sanguíneo (Kaur, Gupta, 2002).

Muitos fatores contribuem para o desenvolvimento de constipação intestinal, particularmente no envelhecimento, como mudanças na dieta e na ingestão de fluidos, diminuição na ingestão de produtos contendo fibras, ingestão de medicamentos, diminuição da motilidade intestinal e inatividade física. Diversos estudos em humanos sugerem que a fermentação de carboidratos estimula a motilidade do cólon (Kaur, Gupta, 2002).

\section{OS PREBIÓTICOS E O ESTÍMULO DA BIODISPONIBILIDADE DE DETERMINADOS MINERAIS E A INFLUÊNCIA SOBRE O METABOLISMO LIPÍDICO}

Diversos estudos com ratos e hamsters e alguns com humanos mostraram que a oligofrutose e/ou inulina aumenta a biodisponibilidade de cálcio (Roberfroid, 2002). O aumento da biodisponibilidade do cálcio poderia ser devido à transferência desse mineral do intestino delgado para o grosso e do efeito osmótico da inulina e da oligofrutose, o qual resultaria na transferência de água para o intestino grosso, permitindo, assim, que o cálcio se torne mais solúvel. A melhor biodisponibilidade do cálcio no cólon poderia ser, também, resultante da hidrólise do complexo cálcio-fitato, por ação de fitases liberadoras de cálcio bacterianas. A melhor absorção foi associada à diminuição de $\mathrm{pH}$ nos conteúdos do íleo, ceco e cólon. Essa diminuição resulta em aumento na concentração de minerais ionizados, condição esta que facilita a difusão passiva, a hipertrofia das paredes do ceco e o aumento da concentração de ácidos graxos voláteis, sais biliares, cálcio, fósforo, fosfato e, em menor grau, magnésio, no ceco (Kaur, Gupta, 2002).

Enquanto o efeito sobre a colesterolemia é controverso, o efeito hipolipidêmico da inulina e da oligofrutose foi observado em alguns estudos com ratos. Dados experimentais conduziram à formulação da hipótese de que os frutooligossacarídeos poderiam reduzir a capacidade lipogênica hepática, através da inibição da expressão gênica das enzimas lipogênicas, resultando em secreção reduzida de lipoproteínas de muito baixa densidade (VLDL)triacilglicerol. Essa inibição poderia ser conseguida via produção de ácidos graxos de cadeia curta ou via modulação da insulinemia, através de mecanismos ainda não identificados, mas que estão sendo investigados (Roberfroid, 2002; Kaur, Gupta, 2002; Delzenne et al., 2002).

Por outro lado, deve ser salientado que tentativas de reproduzir efeitos similares aos observados em ratos, em humanos, com a administração de inulina e oligofrutose, geraram resultados conflitantes (Williams, Jackson, 2002). Essa disparidade de resultados poderia ser atribuída ao emprego de doses bastante inferiores nesses estudos, uma vez que grande parte dos indivíduos apresentava sintomas gastrintestinais adversos, com o consumo diário de doses superiores a $30 \mathrm{~g}$ de inulina. Deste modo, estudos futuros sobre o efeito hipolipidêmico da inulina em humanos deverão levar em conta as características dos indivíduos selecionados, a duração do estudo e o histórico do indivíduo em termos de dieta, uma vez que essas são importantes variáveis que podem exercer influências consideráveis sobre as enzimas (Kaur, Gupta, 2002). 


\section{OS PREBIÓTICOS E A EXCREÇÃO DE NITROGÊNIO E A GLICEMIA}

Estudos em ratos mostraram que o consumo de inulina e oligofrutose reduz a uremia e transfere boa parte da excreção de nitrogênio do rim para o cólon. Entretanto, a extrapolação desses resultados para o que ocorre no homem é questionável, tendo em vista as diferenças na estrutura do trato digestivo e na microbiota do cólon (Kaur, Gupta, 2002).

O efeito da inulina e da oligofrutose sobre a glicemia e a insulinemia ainda não foi elucidado e os dados disponíveis a esse respeito são, algumas vezes, contraditórios, indicando que esses efeitos dependem da condição fisiológica (em jejum ou estado pós-prandial) ou de doença (diabetes). É possível que, como ocorre no caso de outras fibras, a inulina e a oligofrutose influenciem na absorção de macronutrientes, especialmente de carboidratos, retardando o esvaziamento gástrico e/ou diminuindo o tempo de trânsito no intestino delgado. Adicionalmente, uma gliconeogênese induzida por inulina e oligofrutose poderia ser mediada por ácidos graxos de cadeia curta, especialmente o propionato (Kaur, Gupta, 2002).

\section{FREQÜÊNCIA E DOSE DE INGESTÃO DE PROBIÓTICOS E PREBIÓTICOS. PRINCIPAIS CRITÉRIOS PARA A SELEÇÃO DE PROBIÓTICOS}

Para garantir um efeito contínuo, tanto os probióticos quanto os prebióticos devem ser ingeridos diariamente. Alterações favoráveis na composição da microbiota intestinal foram observadas com doses de $100 \mathrm{~g}$ de produto alimentício contendo $10^{9}$ unidades formadoras de colônias (ufc) de microrganismos probióticos $\left(10^{7} \mathrm{ufc} / \mathrm{g}\right.$ de produto) e com doses de 5 a $20 \mathrm{~g}$ de inulina e/ou oligofrutose, geralmente com a administração durante o período de 15 dias. Assim sendo, para serem de importância fisiológica ao consumidor, os probióticos devem alcançar populações acima de $10^{6}$ a $10^{7}$ $\mathrm{ufc} / \mathrm{g}$ ou $\mathrm{mL}$ de bioproduto. Para garantirem o estímulo da multiplicação de bifidobactérias no cólon, doses diárias de 4 a 5 g de inulina e/ou oligofrutose são eficientes (Jelen, Lutz, 1998; Charteris et al., 1998; Niness, 1999; Roberfroid, 1999).

A seleção de bactérias probióticas tem como base os seguintes critérios preferenciais: o gênero ao qual pertence a bactéria ser de origem humana, a estabilidade frente a ácido e a bile, a capacidade de aderir à mucosa intestinal e de colonizar, ao menos temporariamente, o trato gastrintestinal humano, a capacidade de produzir compostos antimicrobianos e ser metabolicamente ativo no intestino. Outros critérios fundamentais são: a segurança para uso humano, o histórico de não patogenicidade e não estarem associadas a outras doenças, tais como endocardite, além da ausência de genes determinantes da resistência aos antibióticos (Collins, Thornton, Sullivan, 1998; Lee et al., 1999; Saarela et al., 2000; Stanton et al., 2003).

Entretanto, deve ser salientado que os probióticos devem, necessariamente, resultar em efeitos benéficos mensuráveis sobre a saúde, substanciados por estudos conduzidos no hospedeiro ao qual ele se destina. Em outras palavras, probióticos destinados para o uso em humanos requerem comprovação da eficácia através de ensaios em humanos (Food and Agriculture Organization of United Nations; World Health Organization, 2001; Sanders, 2003). Outrossim, um critério definitivo para a seleção de cepas probióticas irá depender da indicação clínica, além de considerações de segurança ou biológicas, como a capacidade de sobreviver ao trânsito gastrintestinal e a tolerância à acidez e à bile. Adicionalmente, não se pode aceitar o fato de que uma determinada cepa probiótica será efetiva para todos os indivíduos ou mesmo para um mesmo indivíduo em diferentes fases de uma doença (Shanahan, 2002).

\section{CRITÉRIOS PARA A ESCOLHA DE PROBIÓTICOS PARA A FABRICAÇÃO DE UM PRODUTO ALIMENTÍCIO}

O potencial probiótico pode diferir até mesmo para diferentes cepas de uma mesma espécie. Cepas de uma mesma espécie são incomparáveis e podem possuir áreas de aderência distintas, efeitos imunológicos específicos e seus mecanismos de ação sobre a mucosa saudável e a inflamada podem ser distintos (Isolauri, Salminen, Ouwehand, 2004).

Para a utilização de culturas probióticas na tecnologia de fabricação de produtos alimentícios, além da seleção de cepas probióticas para uso em humanos, através dos critérios mencionados anteriormente, as culturas devem ser empregadas com base no seu desempenho tecnológico. Culturas probióticas com boas propriedades tecnológicas devem apresentar boa multiplicação no leite, promover propriedades sensoriais adequadas no produto e ser estáveis e viáveis durante armazenamento. Desta forma, podem ser manipuladas e incorporadas em produtos alimentícios sem perder a viabilidade e a funcionalidade, resultando em produtos com textura e aroma adequados (Oliveira et al., 2002). Além disso, com relação às perspectivas de processamento de alimentos, é desejável que essas cepas sejam apropriadas para a produção industrial em larga escala, resistindo a condições de processamento como a liofilização ou secagem por "spray drying" (Stanton et al., 2003). 
Uma seleção adequada de cepas deve ser conduzida para o processamento de produtos lácteos probióticos (Vinderola, Reinheimer, 2003). A sobrevivência das bactérias probióticas no produto alimentício é fundamental, necessitando alcançar populações suficientemente elevadas (tipicamente acima de $10^{6} \mathrm{UFC} / \mathrm{ml}$ ou g) para ser de importância fisiológica ao consumidor (Jelen, Lutz, 1998). $\mathrm{O}$ consumo de quantidades adequadas dos microrganismos probióticos desejados nos bioprodutos $\left(10^{9}\right.$ a $10^{10}$ UFC / $100 \mathrm{~g}$ de produto) são suficientes para a manutenção das concentrações ativas fisiologicamente (quantidade intestinal de $10^{6}$ a $10^{7} \mathrm{UFC} / \mathrm{g}$ ) in vivo (Charteris et al., 1998).

Esses alimentos devem permanecer com algumas características inalteradas após a adição do microrganismo para serem considerados probióticos como, por exemplo, conter pelo menos $10^{7} \mathrm{UFC} / \mathrm{g}$ de bactérias probióticas viáveis no momento da compra do produto. Esta é uma concentração recomendada por alguns autores (Rybka, Fleet, 1997; Vinderola, Reinheimer, 2000). Entretanto, vários autores propõem que a dose mínima diária da cultura probiótica considerada terapêutica seja de $10^{8}$ e $10^{9}$ UFC, o que corresponde ao consumo de $100 \mathrm{~g}$ de produto contendo $10^{6}$ a $10^{7} \mathrm{UFC} / \mathrm{g}$ (Lee, Salminen, 1995; Blanchette et al., 1996; Hoier et al., 1999).

\section{PRINCIPAIS APLICAÇÕES DE PROBIÓTICOS E PREBIÓTICOS NA INDÚSTRIA DE ALIMENTOS}

Inúmeros lacticínios probióticos são disponíveis comercialmente e a variedade desses produtos continua em expansão (Stanton et al., 2003). Muita pesquisa em termos de probióticos encontra-se voltada para produtos como leites fermentados e iogurtes, sendo estes os principais produtos comercializados no mundo, contendo culturas probióticas. Outros produtos comerciais contendo essas culturas incluem sobremesas à base de leite, leite em pó destinado a recémnascidos, sorvetes, sorvetes de iogurte e diversos tipos de queijo, além de produtos na fórmula de cápsulas ou produtos em pó para serem dissolvidos em bebidas frias, alimentos de origem vegetal fermentados e maionese (Stanton et al., 1998; Gardiner et al., 1999; Ingham, 1999; Davidson et al., 2000; Oliveira et al., 2002; Stanton et al., 2003).

Diversos tipos de queijo foram testados como veículos para cepas probióticas de Lactobacillus e de Bifidobacterium, revelando-se apropriados, entre eles, o Cheddar (Dinakar, Mistry, 1994; Gardiner et al., 1998; Mc Brearty et al., 2001), o Gouda (Gomes, Vieira, Malcata, 1998); o Crescenza (Gobbetti et al., 1997), o Árzúa-Ulloa (Menéndez et al., 2000), o Caciocavallo Pugliese (Gobbetti et al., 2002) e queijos frescos (Roy, Mainville, Mondou, 1997; Vinderola et al., 2000), incluindo o Minas frescal
(Buriti et al., 2005a; Buriti, Rocha, Saad, 2005b).

Entretanto, é importante salientar que um produto probiótico deve conter uma ou mais cepas bem definidas, uma vez que os efeitos probióticos são específicos para determinadas cepas em especial. Assim sendo, a validação da função probiótica ou o monitoramento do impacto probiótico de uma preparação de microrganismos com uma composição desconhecida é cientificamente inaceitável (Sanders, 2003).

Os frutanos são não cariogênicos, uma vez que não são utilizados como substrato por Streptococcus mutans, microrganismo responsável pelo aparecimento de cárie. Em virtude de possuírem cadeias de diferentes tamanhos, a inulina e a oligofrutose conferem propriedades distintas aos produtos alimentícios aos quais são adicionadas (Kaur, Gupta, 2002).

A oligofrutose, composta de oligômeros de cadeias curtas, possui propriedades similares às do açúcar e de xaropes de glicose, apresentando 30 a $50 \%$ do poder adoçante e maior solubilidade que o açúcar. Sendo assim, esse frutano é freqüentemente empregado em conjunto com edulcorantes de alto poder adoçante, para substituir o açúcar, resultando em um perfil adoçante bem balanceado. A oligofrutose também é utilizada no sentido de conferir consistência a produtos lácteos, maciez a produtos de panificação, diminuir o ponto de congelamento de sobremesas congeladas, conferir crocância a biscoitos com baixo teor de gordura e, além disso, substituir o açúcar também no sentido de atuar como ligante em barras de cereais (Kaur, Gupta, 2002).

Constituída de cadeias longas, a inulina é menos solúvel que a oligofrutose e, quando dispersa na água ou no leite, forma microcristais que interagem para dar origem a uma textura cremosa. Conseqüentemente, é empregada como substituto de gordura em produtos lácteos, patês, molhos, recheios, coberturas, sobremesas congeladas e produtos de panificação (Kaur, Gupta, 2002).

\section{POSSÍVEIS EFEITOS ADVERSOS DOS PREBIÓTICOS E PROBIÓTICOS}

Testes padrões de toxicidade, conduzidos com frutanos do tipo inulina em doses bastante superiores às recomendadas, não detectaram evidências de toxicidade, carcinogenicidade ou genotoxicidade. Assim como no caso dos demais tipos de fibra, o consumo de quantidades excessivas de prebióticos pode resultar em diarréia, flatulência, cólicas, inchaço e distensão abdominal, estado este reversível com a interrupção da ingestão. Entretanto, a dose de intolerância é bastante alta, permitindo uma faixa de dose terapêutica bastante ampla. Além disso, esses 
sintomas gastrintestinais subjetivos são dificilmente mensuráveis (Carabin, Flamm, 1999; Holzapfel, Schillinger, 2002). Quanto aos probióticos, estudos clínicos controlados com lactobacilos e bifidobactérias não revelaram efeitos maléficos causados por esses microrganismos. Efeitos benéficos causados por essas bactérias foram observados durante o tratamento de infecções intestinais, incluindo a estabilização da barreira da mucosa intestinal, prevenção da diarréia e melhora da diarréia infantil e da associada ao uso de antibióticos (Lee et al., 1999).

Paralelamente, apesar de muitas cepas de bactérias láticas, particularmente as de Lactobacillus spp., serem resistentes a determinados antibióticos, essa resistência normalmente não é mediada por plasmídios, não sendo transmissível. Entretanto, há descrição de cepas portadoras de plasmídios de resistência, particularmente cepas de Enterococcus resistentes à vancomicina. Cepas com plasmídios de resistência não devem ser empregadas como probióticos humanos ou animais, por serem, possivelmente, capazes de transmitir os fatores de resistência para bactérias patogênicas, dificultando a cura de infecções (Salminen et al., 1998; O’Brien et al., 1999; Saarela et al., 2000).

Apesar das culturas probióticas de Lactobacillus spp. e de Bifidobacterium spp. serem consideradas seguras (GRAS - "generally recognized as safe"), é necessária a determinação da segurança na utilização da cepa antes do lançamento e da divulgação de um novo produto. Assim, uma avaliação crítica da segurança tornará os benefícios dos probióticos acessíveis ao consumidor (Salminen et al., 1998; O’Brien et al., 1999).

\section{CONCLUSÃO}

Uma microbiota intestinal saudável e microecologicamente equilibrada resulta em um desempenho normal das funções fisiológicas do hospedeiro, o que irá assegurar melhoria na qualidade de vida do indivíduo. Este resultado é de suma importância, particularmente nos dias de hoje, em que a expectativa de vida aumenta exponencialmente. O papel direto dos microrganismos probióticos e indireto dos ingredientes prebióticos, no sentido de propiciar, no campo da nutrição preventiva, essa microbiota intestinal saudável e equilibrada ao hospedeiro, já está bem estabelecido. O efeito dos microrganismos probióticos e dos ingredientes prebióticos pode ser potencializado, através de sua associação, dando origem aos alimentos funcionais simbióticos. Apenas uma pequena fração dos mecanismos para a ocorrência dos efeitos probióticos e prebióticos foi elucidada. Entretanto, estudos nesse sentido são cada vez mais intensos. Melhor compreensão sobre a interação entre os compostos vegetais não-digeríveis, seus metabólitos intestinais, a microbiota intestinal e o hospedeiro abrirá novas possibilidades de produzir novos ingredientes para produtos alimentícios nutricionalmente otimizados que promovem a saúde do hospedeiro, através de reações microbianas no intestino.

\section{AGRADECIMENTOS}

A autora agradece à Fundação de Amparo à Pesquisa do Estado de São Paulo pelo auxílio financeiro (Processo $03 / 13748-1$ ).

\section{ABSTRACT}

\section{Probiotics and Prebiotics: the state of the art}

The gut microbiota plays an important role in both human health and disease, and the supplementation of the diet with probiotics and prebiotics may ensure an appropriate equilibrium of this microbiota. Probiotics are live microorganisms that, when administered in adequate amounts, confer a health benefit on the host. Prebiotics are nondigestible carbohydrates that beneficially affect the host by selectively stimulating the growth and/or activity of a limited number of bacteria present in the colon. A product referred as symbiotic is one in which probiotics and prebiotics are combined. This article presents the state of the art about probiotics and prebiotics, reporting new concepts, the benefits these food ingredients provide for the human health, and the possible mechanisms involved, discussing health claims attributed to them, and pointing out recent findings reported, based on experimental scientific evidence. Other aspects, such as selection and applications of probiotics and prebiotics are also discussed.

UNITERMS: Probiotics. Prebiotics. Functional food. Lactobacillus. Bifidobacterium. Oligosaccharides.

\section{REFERÊNCIAS BIBLIOGRÁFICAS}

BIEDRZYCKA, E.; BIELECKA, M. Prebiotic effectiveness of fructans of different degrees of polymerization. Trends Food Sci. Technol., Amsterdam, v.15, p.170-175, 2004.

BIELECKA, M.; BIEDRZYCKA, E.; MAJKOWSKA, A Selection of probiotics and prebiotics for synbiotics and confirmation of their in vivo effectiveness. Food Res. Int., Amsterdam, v.35, n.2/3, p.125-131, 2002. 
BLANCHETTE, L.; ROY, D.; BELANGER, G.; GAUTHIER, S.F. Production of cottage cheese using dressing fermented by bifidobacteria. J. Dairy Sci., Lancaster, v.79, p.8-15, 1996.

BURITI, F.C.A.; ROCHA, J.S.; ASSIS, E.G.; SAAD, S.M.I. Probiotic potential of Minas fresh cheese prepared with the addition of Lactobacillus paracasei. Lebensm. Wiss. Tech., Amsterdam, v.38, n.2, p.173-180, $2005 a$.

BURITI, F.C.A.; ROCHA, J.S.; SAAD, S.M.I. Incorporation of Lactobacillus acidophilus in Minas fresh cheese and its implications for textural and sensorial properties during storage. Int. Dairy J., Amsterdam, v.15, n. 12, p. 1279-1288, 2005.

CALDER, P.C.; KEW, S. The immune system: a target for functional foods? Br. J. Nutr., Wallingford, v.88, suppl.1, p.S165-S176, 2002.

CARABIN, I.G.; FLAMM, W.G. Evaluation of safety of inulin and oligofructose as dietary fiber. Regul. Toxicol. Pharmacol., New York, v.30, p.268-282, 1999.

CHARTERIS, W.P.; KELLY, P.M.; MORELLI, L.; COLLINS, J.K. Ingredient selection criteria for probiotic microorganisms in functional dairy foods. Int. J. Dairy Technol., Long Hanborough, v.51, n.4, p.123-136, 1998.

COLLINS, J.K.; THORNTON, G.; SULLIVAN, G.O. Selection of probiotic strains for human applications. Int. Dairy J., Amsterdam, v.8, p.487-490, 1998.

CRITTENDEN, R.G. Prebiotics. In: TANNOCK, G.W., ed. Probiotics: a critical review. Norfolk: Horizon Scientific Press, 1999. p.141-156.

CUMMINGS, J.H.; MACFARLANE, G.T. Gastrointestinal effects of prebiotics. Br. J. Nutr., Wallingford, v.87, suppl.2, p.S145-S151, 2002.

DAVIDSON, R.H.; DUNCAN, S.E.; HACKNEY, C.R.; EIGEL, W.N.; BOLING, J.W. Probiotic culture survival and implications in fermented frozen yogurt characteristics. J. Dairy Sci., Lancaster, v.83, n.4, p.666$673,2000$.

DELZENNE, N.M.; DAUBIOUL, C.; NEYRINCK, A.; LASA, M.; TAPER, H.S. Inulin and oligofructose modulate lipid metabolism in animals: review of biochemical events and future prospects. Br. J. Nutr., Wallingford, v.87, suppl.1, p.S255-S259, 2002.
DINAKAR, P.; MISTRY, V.V. Growth and viability of Bifidobacterium bifidum in Cheddar cheese. J. Dairy Sci., Savoy, v.77, p.2854-2864, 1994.

FIORAMONTI, J.; THEODOROU, V.; BUENO, L. Probiotics: what are they? What are their effects on gut physiology? Best Pract. Res. Clin. Gastroenterol., London, v.17, p.711-724, 2003.

FOOD AND AGRICULTURE ORGANIZATION OF THE UNITED NATIONS, WORLD HEALTH ORGANIZATION. Evaluation of health and nutritional properties of probiotics in food including powder milk with live lactic acid bacteria. Córdoba, 2001.34p. Disponível em: <ftp://ftp.fao.org/es/esn/food/ probioreport_en.pdf $>$. Acesso em: 03 fev. 2005. [Report of a Joint FAO/WHO Expert Consultation].

FOOKS, L.J.; FULLER, R.; GIBSON, G.R. Prebiotics, probiotics and human gut microbiology. Int. Dairy J., Amsterdam, v.9, p.53-61, 1999.

FULLER, R. Probiotics in man and animals. J. Appl. Bacteriol., Oxford, v.66, p.365-378, 1989.

GARDINER, G.; ROSS, R.P.; COLLINS, J.K.; FITZGERALD, G.; STANTON, C. Development of a probiotic Cheddar cheese containing human-derived Lactobacillus paracasei strains. Appl. Environ. Microbiol., Washington, v.64, p.2192-2199, 1998.

GARDINER, G.E.; ROSS, R.P.; WALLACE, J.M.; SCANLAN, F.P.; JAGERS, P.P.; FITZGERALD, G.F.; COLLINS, J.K.; STANTON, C. Influence of a probiotic adjunct culture of Enterococcus faecium on the quality of cheddar cheese. J. Agric. Food. Chem., Washington, v.47, n.12,p.4907-4916, 1999.

GIBSON, G.R.; FULLER, R. Aspects of in vitro and in vivo research approaches directed toward identifying probiotics and prebiotics for human use. J. Nutr., Bethesda, v.130, p.391S-394S, 2000.

GIBSON, G.R.; ROBERFROID, M.B. Dietary modulation of the human colonic microbiota: introducing the concept of prebiotics. J. Nutr., Bethesda, v.125, p.1401-1412, 1995.

GILLILAND, S.E. Probiotics and prebiotics. In: MARTH, E.H., STEELE, J.L., eds. Applied Dairy Microbiology. New York: Marcel Dekker, 2001. p.327-343. 
GOBBETTI, M.; CORSETTI, A.; SMACCHI, E.; ZOCCHETTI, A.; De ANGELIS, M. Production of crescenza cheese by incorporation of bifidobacteria. $J$. Dairy Sci., Lancaster, v.81, p.37-47, 1997.

GOBBETTI, M.; MOREA, M.; BARUZZI, F.; CORBO, M.R.; MATARANTE, A.; CONSIDINE, T.; Di CAGNO, R.; GUINEE, T.; FOX, P.F. Microbiological, compositional, biochemical and textural characterisation of Caciocavallo Pugliese cheese during ripening. Int . Dairy J., Amsterdam, v.12, p.511-523, 2002.

GOMES, A.M.P.; VIEIRA, M.M.; MALCATA, F.X. Survival of probiotic microbial strains in a cheese matrix during ripening: simulation of rates of salt diffusion and microorganism survival. J. Food Eng., Kidlington, v.36, p.281-301, 1998.

GUARNER, F.; MALAGELADA, J.R. Gut flora in health and disease. Lancet, London, v.360, p.512-518, 2003.

HIRAYAMA, K.; RAFTER, J. The role of probiotic bacteria in cancer prevention. Microbes Infect., Paris, v.2, p.681$686,2000$.

HOIER, E.; JANZEN, T.; HENRIKSEN, C.M.; RATTRAY, F.; BROCKMANN, E.; JOHANSEN, E. The production, application and action of lactic cheese starter cultures. In: LAW, B.A., ed. Technology of cheesemaking. Boca Raton: CRC Press, 1999. p.99-131.

HOLZAPFEL, W.H.; SCHILLINGER, U. Introduction to pre- and probiotics. Food Res. Int., Amsterdam, v.35, n.2/3, p.109-116, 2002.

INGHAM, S.C. Use of modified Lactobacillus selective medium and Bifidobacterium iodoacetate medium for differential enumeration of Lactobacillus acidophilus and Bifidobacterium spp. in powdered nutritional products. J. Food Prot., Des Moines, v.62, n.1, p.77-80, 1999.

ISOLAURI, E.; SALMINEN, S.; OUWEHAND, A.C. Probiotics. Best Pract. Res. Clin. Gastroenterol., London, v.18, n.2,p.299-313, 2004.

JELEN, P.; LUTZ, S. Functional milk and dairy products. In: MAZZA, G., ed. Functional foods: biochemical and processing aspects. Lancaster: Technomic Publishing, 1998. p.357-381.
KAUR, I.P.; CHOPRA, K.; SAINI, A. Probiotics: potential pharmaceutical applications. Eur. J. Pharm. Sci., Amsterdam, v.15, p.1-9, 2002.

KAUR, N.; GUPTA, A.K. Applications of inulin and oligofructose in health and nutrition. J. Biosci., Bangalore, v.27, p.703-714, 2002.

KLAENHAMMER, T.R. Probiotics and prebiotics. In: DOYLE, M.P.; BEUCHAT, L.R.; MONTVILLE, T.J. Food microbiology: fundamentals and frontiers. 2.ed. Washington:ASM, 2001.p.797-811.

KOPP-HOOLIHAN, L. Prophylactic and therapeutic uses of probiotics: a review. J. Am. Diet. Assoc., Chicago, v.101, p.229-241, 2001.

LEE, Y.K.; NOMOTO, K.; SALMINEN, S.; GORBACH, S.L. Handbook of probiotics. New York: Wiley, 1999. $211 \mathrm{p}$

LEE, Y.K.; SALMINEN, S. The coming age of probiotics. Trends Food Sci. Technol., Amsterdam, v.6, p.241-245, 1995.

LOURENS-HATTINGH, A.; VILJOEN, B.C. Yogurt as probiotic carrier food. Int. Dairy J., Amsterdam, v.11, p.1-17, 2001.

MARTEAU, P.; BOUTRON-RUAULT, M.C. Nutritional advantages of probiotics and prebiotics. Br. J. Nutr., Wallingford, v.87, suppl.2, p.S153-S157, 2002.

MATTILA-SANDHOLM, T.; MYLLÄRINEN, P.; CRITTENDEN, R.; MOGENSEN, G., FONDÉN, R.; SAARELA, M. Technological challenges for future probiotic foods. Int. Dairy J., Amsterdam, v.12, p.173-182, 2002.

Mc BREARTY, S.; ROSS, R.P.; FITZGERALD, G.F.; COLLINS, J.K.; WALLACE, J.M.; STANTON, C. Influence of two commercially available bifidobacteria cultures on Cheddar cheese quality. Int. Dairy J., Amsterdam, v.11, p.599-610, 2001.

MENÉNDEZ, S.; CENTENO, J.A.; GODÍNEZ, R.; RODRÍGUEZ-OTERO, J.L. Effect of Lactobacillus strains on the ripening and organoleptic characteristics of Arzúa-Ulloa cheese. Int. J. Food Microbiol., Amsterdam, v.59, p.37-46, 2000. 
MOROTOMI, M. Intestinal bacteria and cancer. In: Yakult Honsha. Intestinal flora and immunity: intestinal infection, allergies, and cancer. Tokyo: Yakult Honsha, 1997. p.35-44.

NINESS, K.R. Inulin and oligofructose: what are they? $J$. Nutr., Bethesda, v.129, suppl.7, p.1402S-1406S, 1999.

O'BRIEN, J.; CRITTENDEN, R.; OUWEHAND, A.C., SALMINEN, S. Safety evaluation of probiotics. Trends Food Sci. Technol., Amsterdam, v.10, p.418-424, 1999.

OLIVEIRA, M.N.; SIVIERI, K.; ALEGRO, J.H.A.; SAAD, S.M.I. Aspectos tecnológicos de alimentos funcionais contendo probióticos. Rev. Bras. Cienc. Farm., São Paulo, v.38, n.1, p.1-21, 2002.

PEREIRA, D.I.A.; GIBSON, G.R. Effects of consumption of probiotics and prebiotics on serum lipid levels in humans. Critical Rev. Biochem. Molec. Biol., v.37, n.4, p.259-281, 2002.

PUUPPONEN-PIMIÄ, R.; AURA, A.M.; OKSMANCALDENTEY, K.M.; MYLLÄRINEN, P.; SAARELA, M.; MATTILA-SANHOLM, T.; POUTANEN, K. Development of functional ingredients for gut health. Trends Food Sci. Technol., Amsterdam, v.13, p.3-11, 2002.

RAFTER, J. Probiotics and colon cancer. Best Pract. Res. Clin. Gastroenterol., Amsterdam, v.17, p.849-859, 2003.

REID, G.; BRUCE, A.W.; FRASER, N.; HEINEMANN, C.; OWEN, J.; HENNING, B. Oral probiotics can resolve urogenital infections. FEMS Immunol. Med. Microbiol., Amsterdam, v.30, p.49-52, 2001.

ROBERFROID, M.B. Prebiotics: preferential substrates for specific germs? Am. J. Clin. Nutr., Bethesda, v.73 (suppl.), p.406-409, 2001.

ROBERFROID, M.B. Concepts in functional foods: the case of inulin and oligofructose. J. Nutr., Bethesda, v.129, suppl.7, p.1398S-1401S, 1999.

ROBERFROID, M.B. Functional food concept and its application to prebiotics. Dig. Liver Dis., Rome, v.34, suppl.2,p.S105-S110, 2002.
ROY, D.; MAINVILLE, I.; MONDOU, F. Selective enumeration and survival of bifidobacteria in fresh cheese. Int. Dairy J., Amsterdam, v.7, p.785-793, 1997.

RYBKA, S.; FLEET, G.H. Populations of Lactobacillus delbrueckii spp. bulgaricus, Streptococcus thermophilus, Lactobacillus acidophilus and Bifidobacterium species in Australian yoghurts. Food Aust., Sydney, v.49, n.10, p.471-475, 1997.

SAARELA, M.; MOGENSEN, G.; FONDÉN, R.; MÄTTÖ, J.; MATTILA-SANDHOLM, T. Probiotic bacteria: safety, functional and technological properties. $J$. Biotech., Amsterdam, v.84, p.197-215, 2000.

SALMINEN, S.; VON WRIGHT, A.; MORELLI, L.; MARTEAU, P.; BRASSART, D.; DE VOS, W.M.; FONDÉN, R.; SAXELIN, M.; COLLINS, K.; MOGENSEN, G.; BIRKELAND, S.E.; MATTILASANDHOLM, T. Demonstration of safety of probiotics: a review. Int. J. Food Microbiol., Amsterdam, v.44, p.93-106, 1998.

SANDERS, M.E. Overview of functional foods: emphasis on probiotic bacteria. Int. Dairy J., Amsterdam, v.8, p.341$347,1998$.

SANDERS, M.E.; KLAENHAMMER, T.R. Invited review: the scientific basis of Lactobacillus acidophilus NCFM functionality as a probiotic. J. Dairy Sci., Savoy, v.84, p.319-331, 2001.

SANDERS, M.E. Probiotics: considerations for human health Nutr. Rev., New York, v.61, n.3, p.91-99, 2003.

SHAH, N.P.; LANKAPUTHRA, W.E.V. Improving viability of Lactobacillus acidophilus and Bifidobacterium spp. in yogurt. Int. Dairy J., Amsterdam, v.7, p.349-356, 1997.

SHANAHAN, F. Probiotics and inflammatory bowel disease: from fads to fantasy to facts and future. Br. J. Nutr., Wallingford, v.88, suppl.1, p.5-9, 2002.

STANTON, C.; DESMOND, C.; COAKLEY, M.; COLLINS, J.K.; FITZGERALD, G.; ROSS, R.P. Challenges facing development of probiotic-containing functional foods. In: FARNWORTH, E.R., ed. Handbook of fermented functional foods. Boca Raton: CRC Press, 2003. p.27-58. 
STANTON, C.; GARDINER, G.; LYNCH, P.B.; COLLINS, J.K.; FITZGERALD, G.; ROSS, R.P. Probiotic cheese. Int. Dairy J., Amsterdam, v.8, p.491-496, 1998.

TUOHY, K.M.; PROBERT, H.M.; SMEJKAL, C.W.; GIBSON, G.R. Using probiotics and prebiotics to improve gut health. Drug Discovery Today, Haywards Heath, v.8, n.15, p.692-700, 2003.

VAN DE WATER, J. Yogurt and immunity: the health benefits of fermented milk products that contain lactic acid bacteria. In: FARNWORTH, E.R., ed. Handbook of fermented functional foods. Boca Raton: CRC Press, 2003.p.113-144.

VERDU, E.F.; COLLINS, S.M. Irritable bowel syndrome. Best Prac. Res. Clin. Gastroent., London, v.18, n.2, p.315-321, 2004.

VINDEROLA, C.G.; PROSELLO, W.; GHIBERTO, D.; REINHEIMER, J.A. Viability of probiotic (Bifidobacterium, Lactobacillus acidophilus and Lactobacillus casei) and nonprobiotic microflora in Argentinian fresco cheese. J. Dairy Sci., Lancaster, v.83, n.9,p.1905-1911, 2000.

VINDEROLA, C.G.; REINHEIMER, J.A. Enumeration of Lactobacillus casei in the presence of L. acidophilus, bifidobacteria and lactic starter bacteria in fermented dairy products. Int. Dairy J., Amsterdam, v.10, p.271-275, 2000.
VINDEROLA, C.G.; REINHEIMER, J.A. Lactic acid starter and probiotic bacteria: a comparative "in vitro" study of probiotic characteristics and biological barrier resistance. Food Res. Int., Amsterdam, v.36, p.895-904, 2003.

VRESE, M.; SCHREZENMEIR, J. Probiotics in nonintestinal infectious conditions. Br. J. Nutr., Wallingford, v.88, suppl.1, p.S59-S66, 2002.

WILLIAMS, C.M.; JACKSON, K.G. Inulin and oligofructose: effects on lipid metabolism from human studies. Br. J. Nutr., Wallingford, v.87, suppl.2, p.S261-S264, 2002.

WOLLOWSKI, L.; RECHKEMMER, G.; POOL-ZOBEL, B.L. Protective role of probiotics and prebiotics in colon cancer. Am. J. Clin. Nutr., Bethesda, v.73, suppl.2, p.451-455, 2001.

ZIEMER, C.J.; GIBSON, G.R. An overview of probiotics, prebiotics and synbiotics in the functional food concept: perspectives and future strategies. Int. Dairy J., Amsterdam, v.8, p.473-479, 1998.

Recebido para publicação em 21 de fevereiro de 2005. Aceito para publicação em 03 de junho de 2005. 